Nat. Hazards Earth Syst. Sci., 10, 421-428, 2010 www.nat-hazards-earth-syst-sci.net/10/421/2010/ (C) Author(s) 2010. This work is distributed under the Creative Commons Attribution 3.0 License.

\title{
Comparison of aerosol optical thickness with in situ visibility data over Cyprus
}

\author{
A. Retalis ${ }^{1}$, D. G. Hadjimitsis ${ }^{2}$, S. Michaelides ${ }^{3}$, F. Tymvios ${ }^{3}$, N. Chrysoulakis ${ }^{4}$, C. R. I. Clayton ${ }^{5}$, and \\ K. Themistocleous ${ }^{2}$ \\ ${ }^{1}$ Institute for Environmental Research and Sustainable Development, National Observatory of Athens, Athens, Greece \\ ${ }^{2}$ Department of Civil Engineering and Geomatics, Cyprus University of Technology, Limassol, Cyprus \\ ${ }^{3}$ Meteorological Service, Nicosia, Cyprus \\ ${ }^{4}$ Institute of Applied and Computational Mathematics, Foundation for Research and Technology - Hellas, Heraklion, \\ Crete, Greece \\ ${ }^{5}$ Department of Civil Engineering and Environment, University of Southampton, Southampton, UK
}

Received: 14 April 2009 - Revised: 15 Feb 2010 - Accepted: 17 February 2010 - Published: 5 March 2010

\begin{abstract}
The monitoring of aerosol concentrations comprises a high environmental priority, particularly in urban areas. Remote sensing of atmospheric aerosol optical thickness (AOT) could be used to assess particulate matter levels at the ground. However, such measurements often need further validation. In this study, aerosol data retrieved from satellite and sun-photometer, on the one hand, and visibility data at various locations in Cyprus, on the other hand, for the period from January to June 2009 are contrasted. The results obtained by the direct comparison between MODIS and handheld sun-photometer AOT data exhibited a significant correlation $(r=0.83)$; these results are in agreement with those reported by the National Aeronautics and Space Administration (NASA). The correlation between sun-photometer AOT and that estimated from visibility measurements was also significant $(r=0.76)$. A direct and significant relationship between MODIS AOT and AOT estimated from visibility values was also found for all the locations used (the correlation coefficient was found to vary from 0.80 to 0.84 ). It is concluded that MODIS AOT data provide accurate information on the aerosol content in Cyprus, while in the absence of such data, visibility measurements could be used as a secondary source of aerosol load information, in terms of aerosol optical thickness, and provide useful information on a near-real time basis, whenever data are available.
\end{abstract}

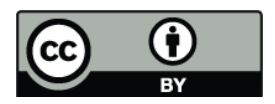

Correspondence to: A. Retalis (adrianr@meteo.noa.gr)

\section{Introduction}

Satellite remote sensing offers opportunities to assess particulate matter by estimating aerosol optical thickness (AOT). AOT is a measure of aerosol loading in the atmosphere. A higher AOT value indicates higher column of aerosol loading and hence lower visibility (Wang and Christopher, 2003). A major challenge in aerosol remote sensing is the quantification of AOT over land, especially in urban environments. Hoff and Christopher (2009) presented a literature review of studies focused on the estimation of ground-level fine particulate matter $\left(\mathrm{PM}_{2.5}\right)$ from columnar AOT.

In the atmosphere, the maximum distance that an object is visible is determined by the scattering and extinction of light by gas molecules and particles. With a few exceptions, the particles are more important in determining visibility. Near centers of human activities, the quantity of suspended particles drastically increases and thus visibility decreases. Therefore, visibility is an easily observable indicator of air quality (Bäumer et al., 2008): a high visibility usually means good air quality (Horvath, 1995).

Bäumer et al. (2008) reported previous studies that dealt with the correlation of visibility or visual range and aerosol properties, most of which refer to the United States and fewer to Europe; Retalis and Michaelides (2009) presented a study of visibility and MODIS AOT data for dust events in Cyprus.

The Moderate Resolution Imaging Spectroradiometer (MODIS) onboard the National Aeronautics and Space Administration's (NASA) Terra and Aqua satellites, launched on 17 December 1999 and 4 May 2002, respectively, have

Published by Copernicus Publications on behalf of the European Geosciences Union. 
been monitoring daily aerosol optical thickness worldwide (Kaufman et al., 2003). The accuracy of satellite-derived AOT is frequently assessed by comparing satellite based AOT with AERONET (AErosol RObotic NETwork - a network of ground-based sun-photometers) or field based sunphotometer AOT.

In this paper, we present the results of aerosol optical thickness measurements taken by MODIS onboard the Terra and Aqua satellites, visibility measurements taken from four meteorological stations and handheld sun-photometer measurements in Cyprus, from January to June 2009. This is the first time that such data are reported for Cyprus. Our objectives in this study are, first to validate the MODIS AOT measurements and, second, to explore the possibilities of establishing near-real time AOT retrievals based on visibility data to assess the atmospheric pollution of the study area, on a local scale.

\section{Data and methodology}

\subsection{MODIS}

NASA's Terra satellite is sun-synchronous and near polarorbiting, with a circular orbit of $705 \mathrm{~km}$ a.s.l. MODIS is capable of scanning 36 spectral bands across a swath $2330 \mathrm{~km}$ wide. MODIS on Terra provides almost complete global coverage every day, with equatorial crossing times at 10:30 a.m. and 10:30 p.m. LT. These measurements are supplemented by a MODIS onboard Aqua, with 01:30 p.m. and 01:30 a.m. overpass times. It should be noted that pm Terra and Aqua equatorial crossing times $(10: 30 \mathrm{pm}$ and $01: 30 \mathrm{pm}$, respectively) correspond to night scenes, when AOT could not be retrieval and therefore are not used in this study.

MODIS measures the total of solar radiance scattered by the atmosphere and light reflected by the ground surface and attenuated by atmospheric transmission. The intensity of surface reflectance depends on the zenith angle, satellite position and the directional reflectance properties of land cover. The algorithm that generates AOT retrievals uses the MODIS spatial resolution of $250 \mathrm{~m}(660 \mathrm{~nm}$ band) and $500 \mathrm{~m}(470$ and $550 \mathrm{~nm}$ bands) and produces a statistically robust product in $10 \mathrm{~km} \times 10 \mathrm{~km}$ resolution.

The Terra and Aqua (MOD04_L2 and MYD04_L2 products) MODIS AOT dataset collection (versions 5.0 and 5.1, respectively) was used for this study. The MODIS darktarget aerosol retrieval algorithms (Remer et al., 2008, 2009) derive aerosol properties over dark land (Levy et al., 2007) and ocean (Remer et al., 2005; Tanré et al., 1997). As stated in Levy et al. (2009), "regardless of surface target, the algorithm carries out the following: 1) aggregates pixel-level spectral reflectance observations (at $500 \mathrm{~m}$ for most channels) into $10 \mathrm{~km} \times 10 \mathrm{~km}$ retrieval regions; 2) discards pixels contaminated by clouds and other factors; 3) truncates the lowest and highest $25 \%$ of the reflectance histogram if the retrieval is over water and the lowest $20 \%$ and highest $50 \%$ if the retrieval is over land; and, finally, 4) compares the average of the remaining values to a lookup table to derive AOT and fine-mode aerosol fraction over water and the fine"model" aerosol fraction over land. Each pixel is assumed to represent a statistical sample of the spectral reflectance over the $10 \mathrm{~km} \times 10 \mathrm{~km}$ region. During the retrieval process (Remer et al., 2009), a wide variety of "quality-assurance" (QA) flags are set, diagnosing any irregularities encountered during the retrieval process".

\subsection{Handheld sun-photometer}

The handheld sun-photometer measures attenuation of the direct sunlight as it passes through the atmosphere. As the aperture of the instrument is small, the light intensity measured by the sun-photometer is usually not influenced by atmospheric scattering, at least for moderate AOT values. The instrument, therefore, measures the total transmittance from which AOT of the atmosphere is derived.

The Microtops II (Solar Light Company, USA) handheld sun-photometer that provides AOT and columnar water vapor from instantaneous measurements at five channels was used in this study. The Microtops II sun-photometer can measure aerosol optical depth and direct solar irradiance and has five optical collimators and narrow band pass filters with internal baffles to prevent internal reflections.

The sun-photometer was mounted on a tripod at a fixed location each time to ensure best results. The collimators and band pass filters capture incoming radiation and radiate it onto an array of photodiodes. The radiation is amplified and converted into a digital signal. In order to get valid results, collection periods could only occur during cloud-free daylight hours and for AOT comparison, at periods coincident with polar orbiting satellites overpasses. A Garmin ${ }^{\circledR}$ GPS 12 Personal Navigator ${ }^{\circledR}$ was connected to the sun-photometer for retrieval of location and time.

Recordings made at Limassol $\left(34.689^{\circ} \mathrm{N}, 33.062^{\circ} \mathrm{E}\right.$; for all locations referred to in this study see Fig. 1) were used in this study. The readings at $500 \mathrm{~nm}$ were used in this study, taken approximately within $15 \mathrm{~min}$ from satellite overpass time on each day with full sunshine.

\subsection{Visibility}

The Meteorological Service of Cyprus carries out routine meteorological observations on a 24-h basis. This includes data collection and archiving of various parameters, such as temperature, relative humidity, wind speed and direction, present weather and horizontal visibility. The recordings of visibility from four stations located at Larnaca $\left(34.883^{\circ} \mathrm{N}\right.$, $33.633^{\circ} \mathrm{E} ; 2 \mathrm{~m}$ a.m.s.l.), Akrotiri $\left(34.583^{\circ} \mathrm{N}, 32.983^{\circ} \mathrm{E}\right.$; $23 \mathrm{~m}$ a.m.s.l.), $\mathrm{Nicosia}\left(35.150^{\circ} \mathrm{N}, 33.400^{\circ} \mathrm{E} ; 162 \mathrm{~m}\right.$ a.m.s.l.) and Paphos $\left(34.716^{\circ} \mathrm{N}, 32.483^{\circ} \mathrm{E} ; 11 \mathrm{~m}\right.$ a.m.s.l.) were used in this study, covering the period from January to June 2009 


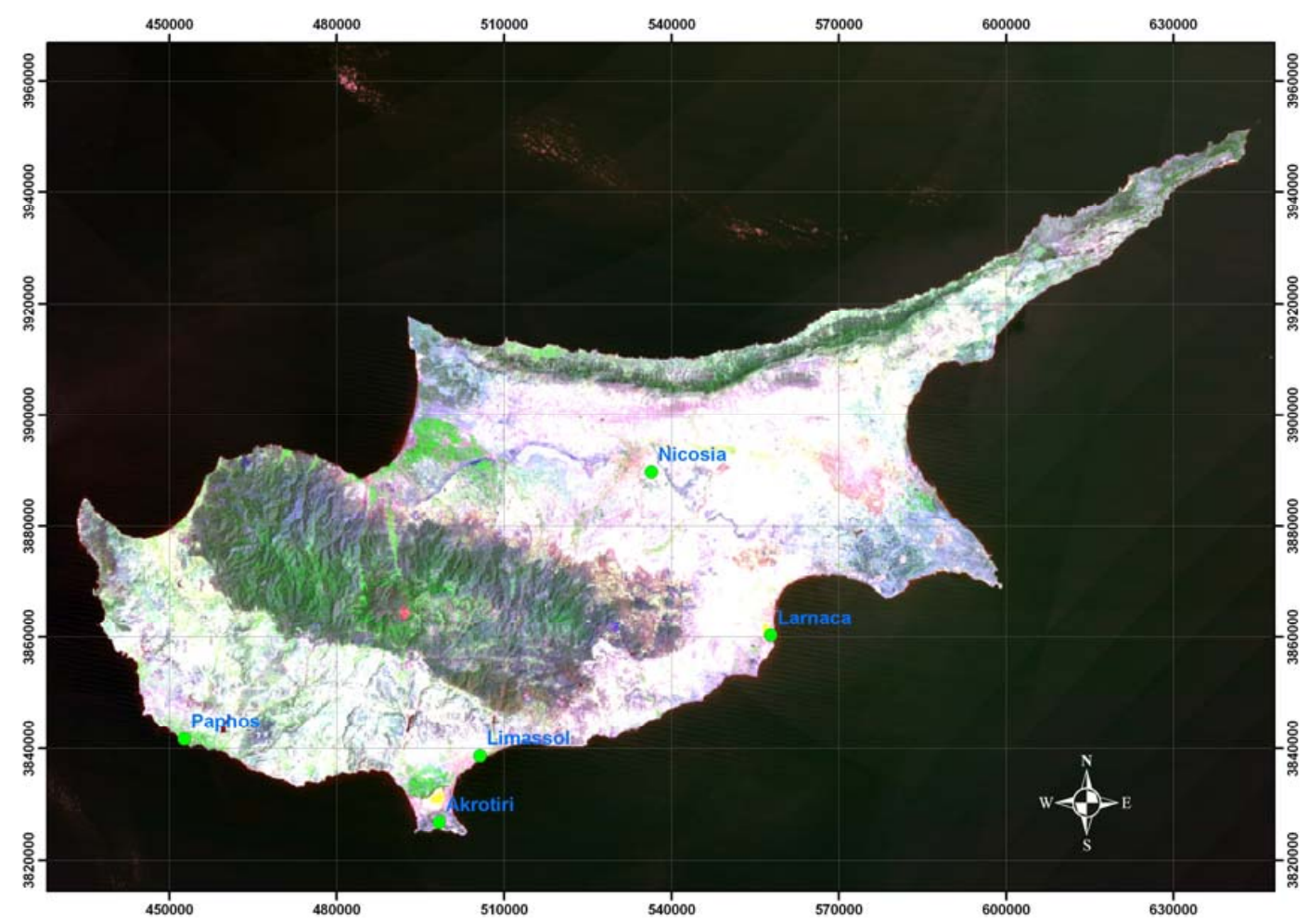

Fig. 1. Map of Cyprus with locations of visibility (Larnaca, Akrotiri, Nicosia, Paphos) and sun-photometer (Limassol) measurements. Coordinates are in UTM (Universal Transverse Mercator).

(see Fig. 1 for the spatial distribution of the locations). The recordings used in the study were taken within $\pm 1 \mathrm{~h}$ from the corresponding MODIS acquisition time.

"Visibility is defined as the maximum distance that an object or details of a complex pattern can be seen. Implications in estimating visibility can either be caused by imperfections of the detection system (e.g. short-sighted people trying to see at large distances) or by interferences of the medium between the object and the observer, as for example when observing a pedestrian in fog" (Horvath, 1995).

The visibility measurements used in this study are taken by experienced human observers. Although such observations are to a certain degree subjective, they undergo several checks before being registered and disseminated. Their major usage is for the needs of civil aviation and are given special consideration, frequently being the result of consultation among the duty observers. The training of professional personnel as far as the recording of visibility is concerned is carried out within the framework of detailed guidance and instructions given by specialized technical manuals on this matter. With standard weather reporting practices, visibility represents the prevailing value in the horizontal direction (World Meteorological Organization, 1995).

\section{Results and discussion}

\subsection{Comparison of MODIS and handheld sun-photometer}

Several studies have been conducted on the retrieval of the accuracy of MODIS AOT by comparing MODIS AOT with AERONET or field based sun-photometer AOT (Schaap et al., 2008; Remer et al., 2005; Levy et al., 2005; Li et al., 2005; Chu et al., 2002). Since launch, validation studies suggested that the expected error over land could be represented by $\Delta($ AOT $)= \pm 0.05 \pm 0.15$. AOT (see Remer et al., 2005).

In this study, one handheld sun-photometer was deployed to measure aerosol optical thickness at Limassol, from January to June 2009. This is the first time that MODIS AOT data over Cyprus are undergone validation. Since no AERONET data were available for Cyprus, a handheld sunphotometer was used to verify and study the aerosol properties from MODIS data. The MODIS dataset was matched to corresponding readings by handheld sun-photometer only if the readings were taken within $15 \mathrm{~min}$ from satellite overpass. Original MODIS and handheld sun-photometer AOT data were used; none of the data were aggregated.

Figure 2 shows the evaluation results of AOT measurements comparisons between the MODIS and handheld sun-photometer data at Limassol. The two variables are 


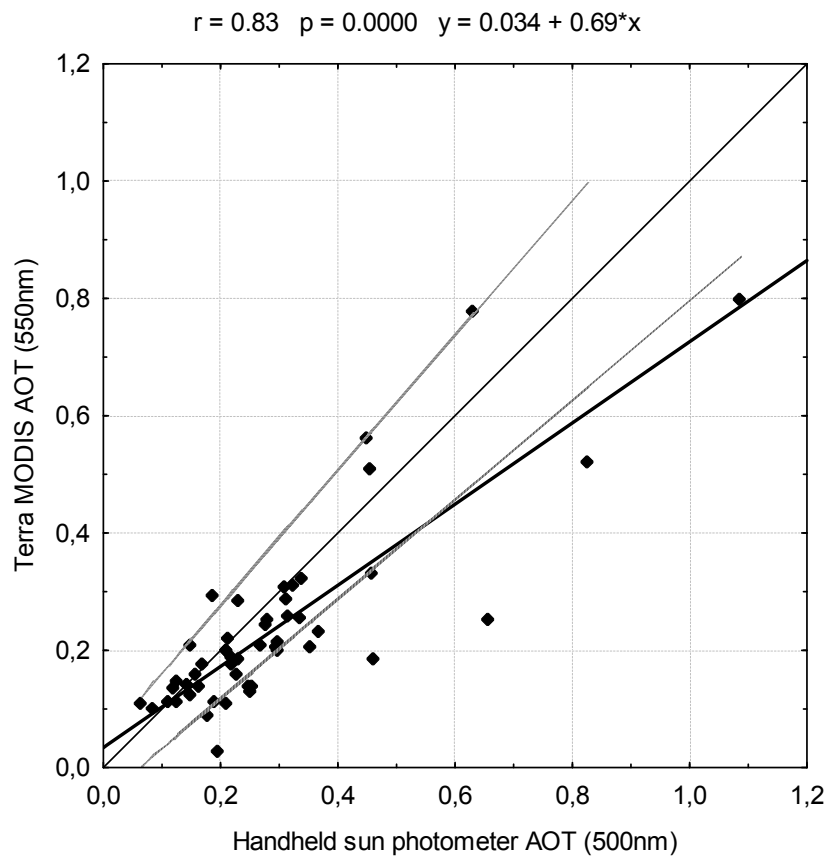

Fig. 2. MODIS aerosol optical thickness retrievals over Limassol as a function of handheld sun-photometer observations collocated in space and time. The regression equation, the correlation coefficient and the p-value are given at the top of the plot. The dashed lines denote the expected uncertainty calculated from prelaunch analysis and the thin solid line the equal axis plot.

strongly correlated (Pearson's $r=0.83$, Spearman's $\rho=0.779$ ); the $\mathrm{p}$-values related to the statistical significance of the positive association were less than 0.0001 indicating very strong evidence against the null hypothesis of no linear association. The linear regression equation derived was $y=\underset{(0.023)}{0.034}+\underset{(0.067)}{0.692 x}$. Standard errors are displayed in parentheses below parameter estimates. The magnitude of the standard error for the intercept term is relatively large so that the evidence against the null hypothesis that the regression line passes through the origin of the axes is weak, according to the associated t-test. Re-estimation without the intercept term resulted in $y=0.775 x$. It was found that the percent$(0.036)$

ages within the expected error lines are $72 \%$, which are in agreement with the pre-launch expectations of $66 \%$ issued by NASA (Remer et al., 2005).

Based on the fact that the MICROTOPS sun-photometer band does not exactly fit with the satellite one (bandwidth), some discrepancies may occurred. Indeed, the authors use the MICROTOPS AOT average value for all the bands in relation with Angstrom coefficient in order to find any errors. However, the AOT difference due to these mismatch discrepancies was very low and negligible.
A few but rather limited handheld sun-photometer measurements were also made in Nicosia and Paphos areas, depicting also high correlation coefficients $(r=0.79$ and $r=0.80$ for Nicosia and Paphos districts, respectively).

\subsection{Comparison of visibility and handheld sun-photometer}

In general, high values of AOT suggest high concentration of aerosols. More aerosols in the atmosphere scatter off light more effectively, hence resulting in lower visibility. In general, AOT measured from satellite and sun-photometers is the aerosol optical thickness corresponding to the vertical path (i.e., this quantity corresponds to the integral of the aerosol extinction coefficient along the atmospheric column). Conversely, visibility data relate to the atmospheric extinction coefficient along a horizontal path.

Vermote et al. (2002) established a relation between visibility and aerosol optical thickness to be used for Visible/Infrared Imager/Radiometer Suite (VIIRS) data onboard the National Polar-orbiting Operational Environmental Satellite System (NPOESS):

$V=3.9449 /\left(\mathrm{AOT}_{550}-0.08498\right)$

where, $V$ is the visibility in kilometres, since the constant 3.9449 is in $\mathrm{km}$, and $\mathrm{AOT}_{550}$ is the aerosol optical thickness at the $550 \mathrm{~nm}$ wavelength. This form is advantageous for VIIRS since it measures $\mathrm{AOT}_{550}$ directly with a band at $555 \mathrm{~nm}$. The above equation is not valid for AOT $\leq 0.08498$, however such AOT values are not observed over the study area. Moreover, the minimum AOT value of 0.1 was used in this study.

The above formula was used in our case in order to estimate AOT at $550 \mathrm{~nm}$ from visibility measurements at Limassol to be further calibrated with AOT derived from handheld sun-photometer data. Sun-photometer data were used when readings were taken within $15 \mathrm{~min}$ from the visibility recordings.

The results of the comparison between the estimated AOT from visibility and handheld sun-photometer AOT data at Limassol are presented in Fig. 3. The analysis showed a high correlation coefficient $(r=0.76)$, statistically significant $(p=0.00000)$. The linear regression equation derived was $y=0.121+0.61 x$.

\subsection{Comparison of MODIS and visibility}

Retalis and Michaelides (2009) presented an analysis of some case studies of dust events at two stations in Cyprus by using MODIS (Terra) AOT measurements and concurrent visibility data. In this study, MODIS (Terra and Aqua) AOT data at $550 \mathrm{~nm}$ at a spatial resolution of $10 \mathrm{~km} \times 10 \mathrm{~km}$ were compared against AOT estimated values from visibility measurements according to the formula suggested by Vermote et al. (2002), taken within an hour of each satellite overpass at four meteorological stations located at Larnaca, Akrotiri, 


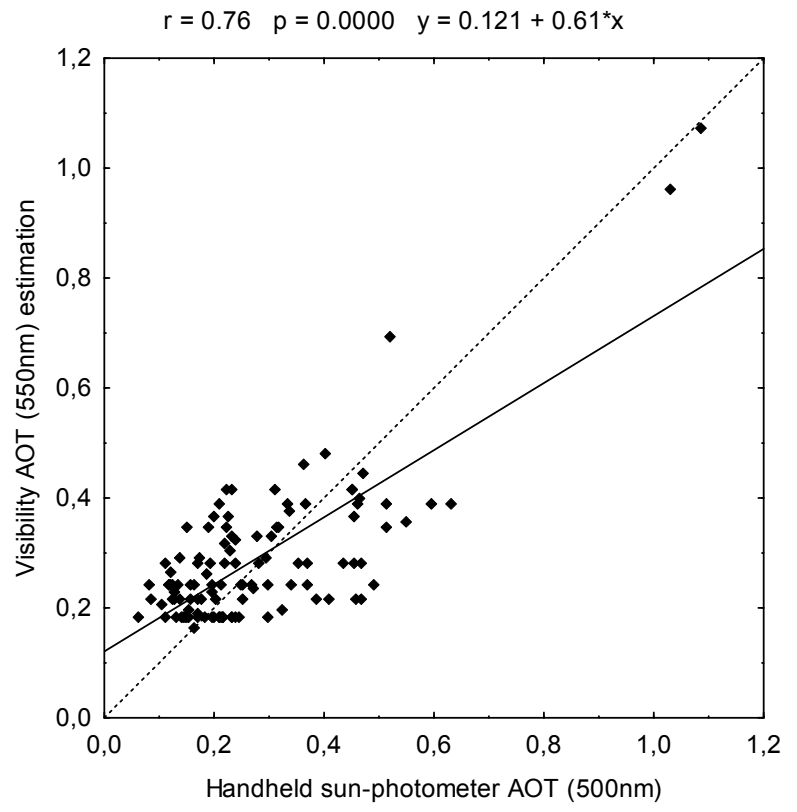

Fig. 3. Aerosol optical thickness retrievals from visibility measurements over Limassol as a function of handheld sun-photometer observations collocated in space and time. The regression equation, the correlation coefficient and the p-value are given at the top of the plot. The dashed line denotes the equal axis plot.

Nicosia, and Paphos. The results (see Figs. 4-7) showed that for all of the four stations, the AOT estimated from visibility and the actual MODIS AOT data were found to be well correlated, with the correlation coefficient varying from 0.80 to 0.82 and 0.80 to 0.84 for Terra and Aqua, respectively. The correlations established were also statistically significant (the value of p-level was used to test the statistical significance). Also, taking into consideration the established regression relationships, it was found that AOT estimated from visibility measurements is better associated with Aqua MODIS AOT data.

The reasons that the correlations found vary could be due to: (1) the coarse spatial resolution of MODIS $(10 \mathrm{~km} \times 10 \mathrm{~km})$ considering that visibility is recorded at a single location; (2) satellite AOT represents measurement of atmospheric aerosol loading in a vertical rather than a horizontal sense in comparison to visibility; and (3) the time gap between the two measurements, since visibility and MODIS AOT are not retrieved at the same time.

Since visibility data are available on an hourly basis, and the correlations found were significant, such AOT estimations could be used, as a secondary source of information, for the study of air quality information over Cyprus, on a daily and local basis. However, it should be noted that caution should be taken in handling such data, since it is only an estimation of AOT and not real measurements.
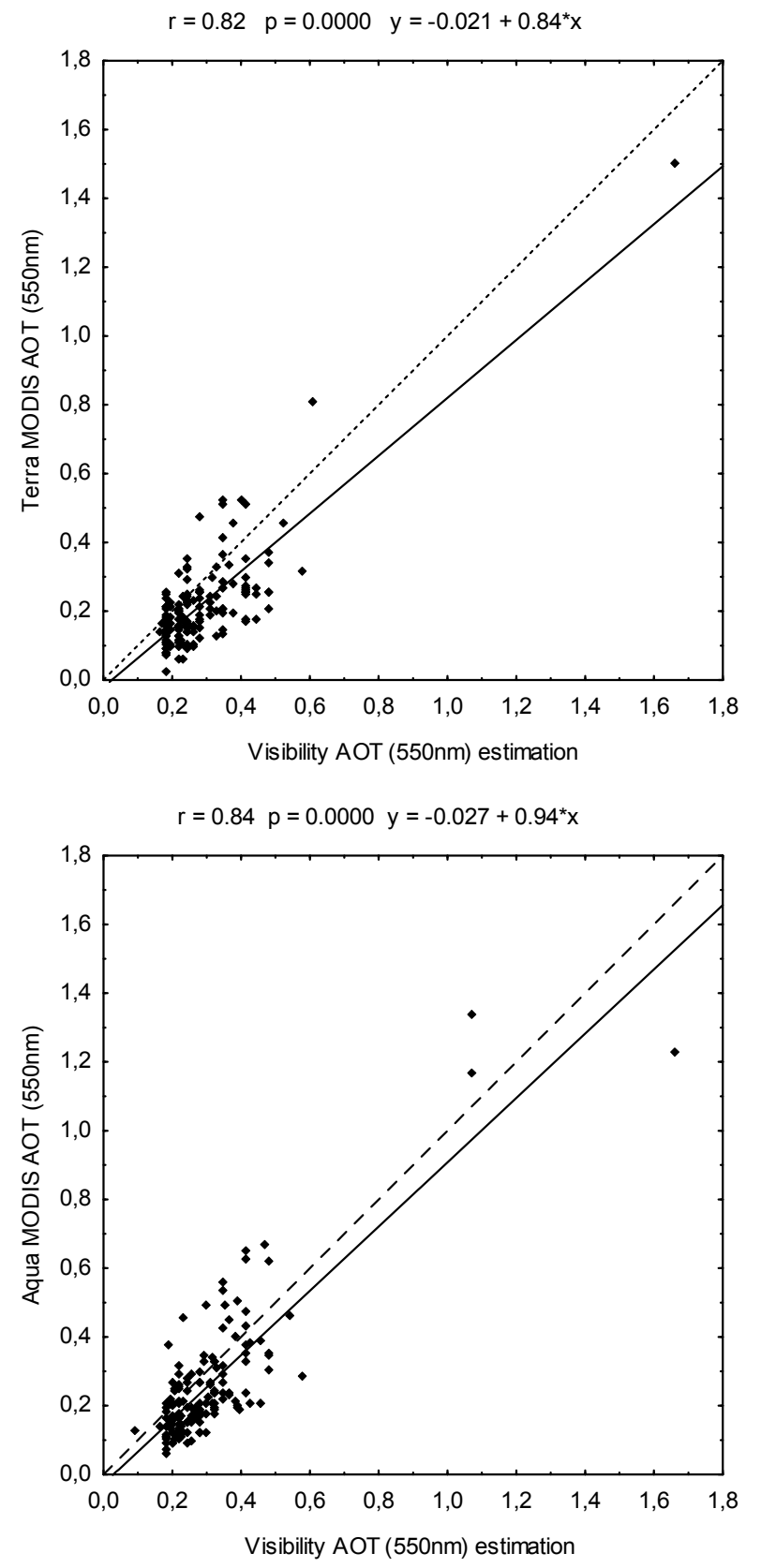

Fig. 4. Relationship between AOT estimated from visibility and actual MODIS measurements at Larnaca. The regression equation, the correlation coefficient and the p-value are given at the top of the plot. The dashed line denotes the equal axis plot.

\section{Conclusions}

An overall study for assessing aerosol optical thickness over Cyprus from January to June 2009 was presented. Satellite, sun-photometer and visibility range data were used to assess aerosol optical thickness. A handheld sun-photometer was used for the validation of both MODIS and visibility data 

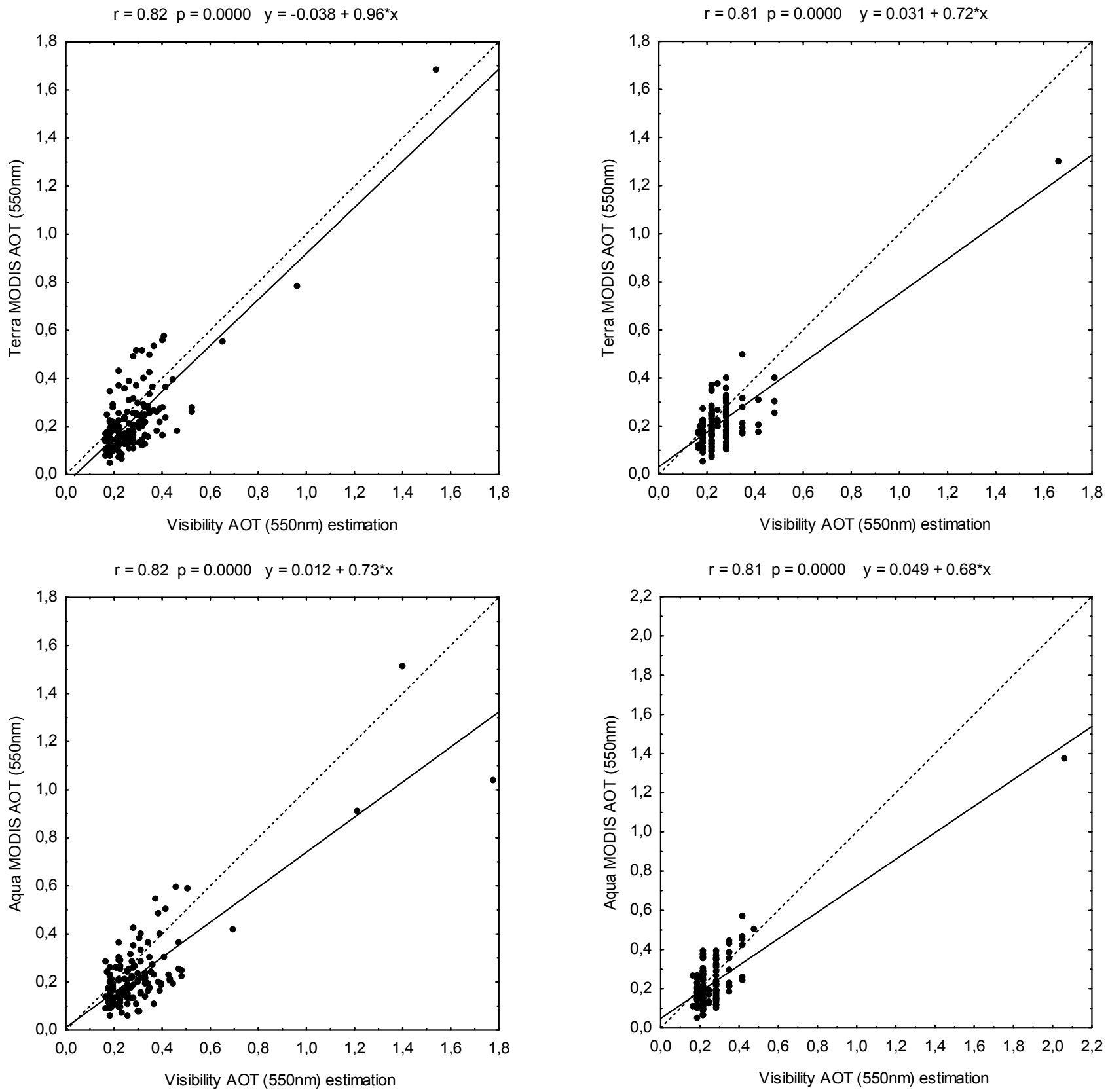

Fig. 5. Same as Fig. 4, but for Akrotiri.

Fig. 6. Same as Fig. 4, but for Nicosia.

at Limassol. In this paper, validation of MODIS AOT retrievals is presented for the first time in Cyprus. It was found that MODIS AOT data are within the expected accuracy as reported by NASA. AOT estimated from visibility was also found to be in good agreement with sun-photometer data.

We also investigated the comparison between MODIS AOT measurements and AOT based on visibility measurements at four meteorological stations. The established relationships were also found to be significant. The differences found could be due to the coarse MODIS AOT spatial resolution $(10 \mathrm{~km} \times 10 \mathrm{~km})$.

It must be clarified that Fig. 3 illustrates retrievals from visibility measurements over Limassol as a function of handheld sun-photometer observations collocated in space and time, while Figs. 4-7 depict the relationship between AOT estimated from visibility and actual MODIS measurements. Thus, Fig. 3 is used to interpret the validation of the AOT estimated from visibility, while the rest of the images are used to examine how AOT estimations could be utilized, as a secondary source of information, for the study of air quality information over Cyprus, on a daily and local basis. The fact that AOT estimated from visibility values is frequent noticed 

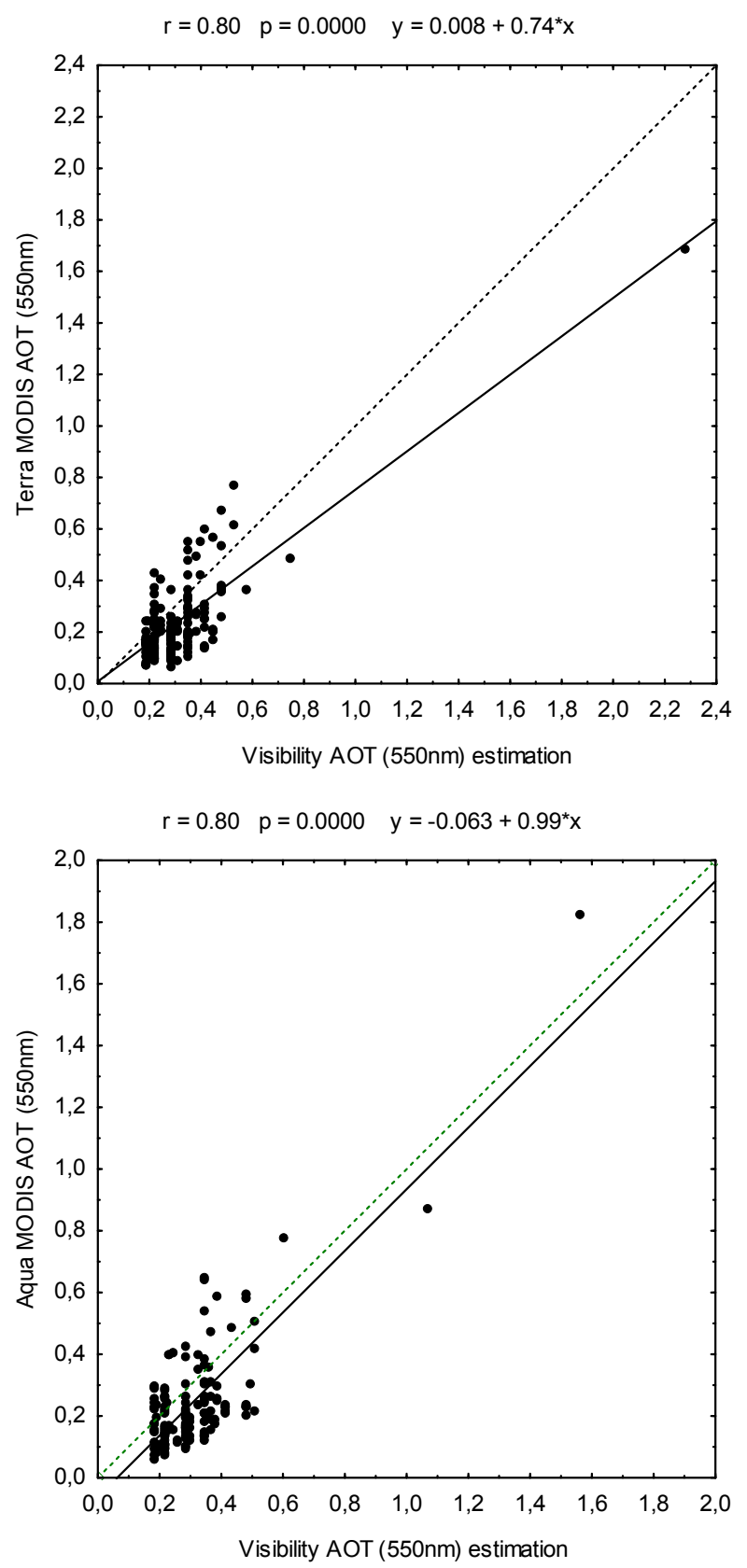

Fig. 7. Same as Fig. 4, but for Paphos.

around the value of 0.2 is due to the fact that the visibility data, referred to the period of our study, were of the order of about $40 \mathrm{~km}$, and hence heavy aerosol loads were not observed.

The results suggest that for the particular times and places, the atmospheric aerosol loading was relatively homogeneous on scales of a few metres to several tens of kilometres, so the handheld sun-photometer and visibility recordings yield AOT values which are representative of the large areas sampled by MODIS.

The major finding derived from this study suggests that MODIS AOT data provide relatively accurate information of the aerosol loading, in terms of aerosol optical thickness, over Cyprus. It was also proved that visibility measurements could be also used as a supplementary source of information of atmospheric loading, although such AOT data retrieval should be handled carefully, as they only provide an estimation of AOT and not a real measurement. The advantage of using visibility data is that such data are available every hour on each day from four meteorological stations, located within a short distance from urban areas. Thus, taking into account all the considerations discussed, an early warning to the authorities could be provided in near-real time intervals following also the analysis of the synoptic situation.

Acknowledgements. The authors acknowledge the financial support of the Cyprus University of Technology (Internal Research Project/Small Size Research Project funded by the Research committee of the Cyprus University of Technology \& D. G. Hadjimitsis Research Activity Funding) and the support provided by the Remote Sensing Laboratory of the Department of Civil Engineering and Geomatics at the Cyprus University of Technology. Partial support was also received from the Cyprus Research Promotion Foundation under contract No. AEIFORIA/ASTI/0308(BE)/01.

Edited by: K. Savvidou

Reviewed by: three anonymous referees

\section{References}

Bäumer, D., Vogel, B., Versick, S., Rinke, R., Möhler, O., and Schnaiter, M.: Relationship of visibility, aerosol optical thickness and aerosol size distribution in an ageing air mass over South-West Germany, Atmos. Environ., 42, 989-998, 2008.

Chu, D. A., Kaufman, Y. J., Ichoku, C., Remer, L. A., Tanré, D., and Holben, B. N.: Validation of MODIS aerosol optical depth retrieval over land, Geophys. Res. Lett., 29(12), 8007, doi:10.1029/2001GL013205, 2002.

Hoff, R. and Christopher, S. A.: Remote sensing of particulate pollution from space: have we reached the promised land?, J. Air Waste Manage., 59, 645-675, 2009.

Horvath, H.: Estimation of the average visibility in central Europe, Atmos. Environ., 29, 241-246, 1995.

Kaufman, Y. J., Ichoku, C., Giglio, L., Korontzi, S., Chu, D. A., Hao, W. M., Li, R.-R., and Justice, C. O.: Fire and smoke observed from the Earth Observing System MODIS instrumentproducts, validation, and operational use, Int. J. Remote Sens., 24, 1765-1781, 2003.

Levy, R. C., Remer, L. A., Martins, J. V., Kaufman, Y. J., PlanaFattori, A., Redemann, J., and Wenny, B.: Evaluation of the MODIS aerosol retrievals over ocean and land during CLAMS, J. Atmos. Sci., 62, 974-992, 2005.

Levy, R. C., Remer, L. A., Mattoo, S., Vermote, E., and Kaufman, Y. $\mathrm{J}$.: Second-generation algorithm for retrieving aerosol properties over land from MODIS spectral reflectance, J. Geophys. Res., 112(D13), D13211, doi:10.1029/2006JD007811, 2007. 
Levy, R. C., Leptoukh, G. G., Kahn, R., Zubko, V., Gopalan, A., and Remer, L. A.: A Critical Look at Deriving Monthly Aerosol Optical Depth From Satellite Data, IEEE T. Geosci. Remote, 47(8), 2942-2956, 2009.

Li, C., Lau, A. K.-H., Mao, J., and Chu, D. A.: Retrieval, Validation, and Application of the 1-km Aerosol Optical Depth From MODIS Measurements Over Hong Kong, IEEE T. Geosci. Remote, 43, 2650-2658, 2005.

Remer, L. A., Kaufman, Y. J., Tanré, D., Mattoo, S., Chu, D. A., Martins, J. V., Li, R.-R., Ichoku, C., Levy, R. C., Kleidman, R. G., Eck, T. F., Vermote, E., and Holben, B. N.: The MODIS Aerosol Algorithm, Products, and Validation, J. Atmos. Sci., 62, 947-973, 2005.

Remer, L. A., Kleidman, R. G., Levy, R. C., Kaufman, Y. J., Tanré, D., Mattoo, S., Martins, J. V., Ichoku, C., Koren, I., Yu, H., and Holben, B. N.: Global aerosol climatology from the MODIS satellite sensors, J. Geophys. Res., 113(D14), D14S07, doi:10.1029/2007JD009661, 2008.

Remer, L. A., Tanré, D., Kaufman, Y., Levy, R., and Mattoo, S.: Algorithm for Remote Sensing of Tropospheric Aerosol from MODIS: Collection 005, Rev. 2, 97 pp, available at: http: //modis-atmos.gsfc.nasa.gov (last access: 14 November 2009), February 2009.
Retalis, A. and Michaelides, S.: Synergetic use of TERRA/MODIS imagery and meteorological data for studying aerosol dust events in Cyprus, Int. J. Environ. Pollut., 36, 139-150, 2009.

Schaap, M., Timmermans, R. M. A, Koelemeijer, R. B. A, de Leeuw, G., and Builtjes, P. J. H.: Evaluation of MODIS aerosol optical thickness over Europe using sun photometer observations, Atmos. Environ., 42, 2187-2197, 2008.

Tanré, D., Kaufman, Y. J., Herman, M., and Mattoo, S.: Remote sensing of aerosol properties over oceans using the MODIS/EOS spectral radiances, J. Geophys. Res., 102(D14), 16971-16988, 1997.

Vermote, E. F., Vibert, S., Kilcoyne, H., Hoyt, D., and Zhao, T.: Suspended Matter. Visible/Infrared Imager/Radiometer Suite algorithm theroretical basis document. SBRS Document \# Y2390, Raytheon Systems Company, Information Technology and Scientific Services, Maryland, 2002.

Wang, J. and Christopher, S. A.: Intercomparison between satellitederived aerosol optical thickness and $\mathrm{PM}_{2.5}$ mass: Implications for air quality studies, Geophys. Res. Lett., 30(21), 2095, doi:10.1029/2003GL018174, 2003.

World Meteorological Organization: Manual on Codes, Suppl. No. 6 (VIII.2007), WMO, Geneva, Switzerland, 1995.

World Meteorological Organization: WMO guide to meteorological instruments and methods of observation, 7th edn., WMO-No. 8, 2008. 